Chapter 14

\title{
Genetic Diversity and Population Structure of the Hotoke Loach, Lefua echigonia, a Japanese Endangered Loach
}

\author{
Noriyuki Koizumi, Masakazu Mizutani, Keiji Watabe, \\ Atsushi Mori, Kazuya Nishida and Takeshi Takemura
}

Additional information is available at the end of the chapter

http://dx.doi.org/10.5772/53022

\section{Introduction}

In Japan, conservation and regeneration projects have been actively conducted for largesized birds such as the Japanese crested ibis, Nipponia Nippon, the oriental white stork, Ciconia boyciana and the intermediate egret, Ardea intermedia (Photo 1) that inhabit rural areas [1, 2]. Many people are highly interested in these projects and a lot of information about growth and breeding for large-sized birds is broadcasted through television, radio and internet media. In such a situation, a conspicuous topic has been found in recent months, that is, 2 individuals of the Japanese crested ibis displayed beriberi symptom along with human being, because of overeating great favorite food that is the Dojo loach, Misgurnus anguillicaudatus. Their beriberi symptom appeared to be caused by eating the Dojo loach raw. The 2 individuals were diagnosed as follows; this beriberi symptom occurred as vitamin B1 in the individual bodies was destroyed by tiaminase enzyme contained in the Dojo loach. At present the two individuals may have completely recovered from the beriberi symptom through vitamin B1 supplementation by injection.

By the way, the presence of 10 or more loach species including the Dojo loach has been observed around paddy fields in rural areas, Japan. Most loach species appear to become food attractive for large-sized birds (Photo 1) [3] and one of the reasons is that the loach species cannot move as rapidly as swimming species such as the Japanese dace, Tribolodon hakonensis and the Ayu, Plecoglossus altivelis altivelis; hence large-sized birds are able to easily catch them. In addition, only the Dojo loach has been investigated, but nutrition contained in this loach was superior to other fish species; for instance, amount of calcium 
in the Dojo was 9 times that of the Japanese ell, Anguilla japonica, and also the Dojo had the most amount of vitamin B2 in all fish $[4,5]$. Actually these precise nutrient components may somewhat differ among the loach species, but their nutrient components could have to be fundamentally similar.

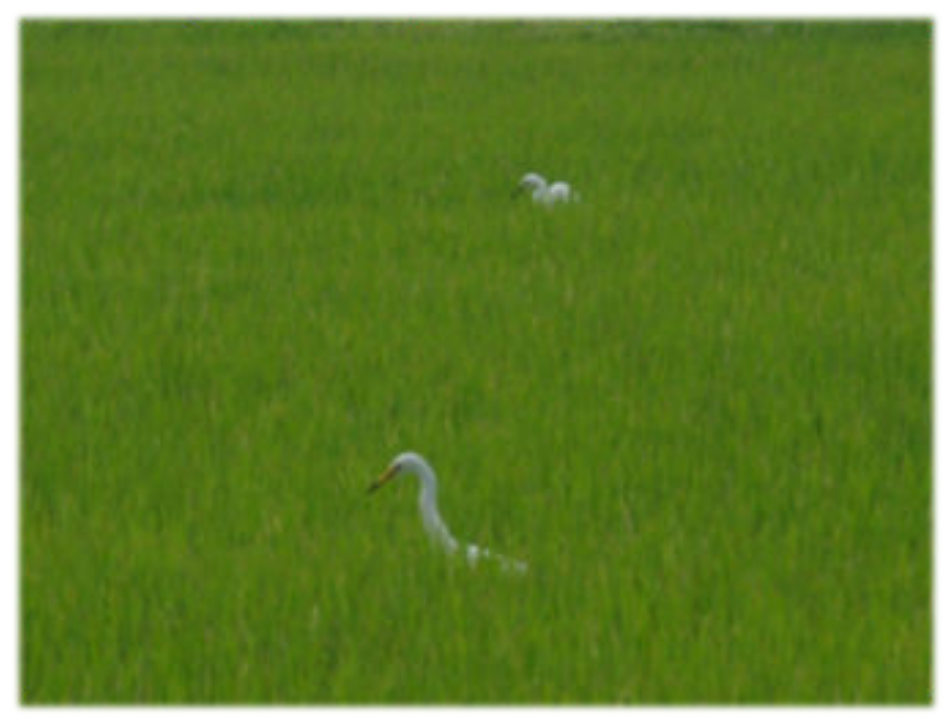

Photo 1. 2 individuals of the intermediate egret, Ardea intermedia that are finding individuals of many loach species as their food in paddy field (unpublished photo)

However, some of the loach species have confronted a kind of serious concerns, especially a decrease in their population size. In Japan, we have conducted many land consolidation projects for rising rice production and easing agricultural works in rural area since 1960s. In land consolidation projects, concrete canals, drops, diversion weirs, etc. have been installed around paddy fields as agricultural infrastructures; therefore not only fish populations and their habitats but also all of ecosystem and biodiversity in rural area have been extremely damaged [6-9].

The Hotoke loach, Lefua echigonia endemic to Japan (the above in Photo 2) has been well known as a representative loach species has been adversely impacted on its habitat due to land consolidation projects. Since populations of this loach have rapidly declined in some rural areas, consequently the Hotoke loach has been designated as an endangered species on the Red List of Japan [10]. Ecology of the loach is briefed as follows; this species is widely distributed across the Honshu Island from the Tohoku region to the Kinki region. They usually inhabits earth canals and ditches around paddy fields into which ground water flows (the bottom in Photo 2) [11, 12]. The Hotoke loach often coexists with the Dojo loach in the habitat and geographic variations for this loach based on morphological characteristics is obscure $[13,14]$. 


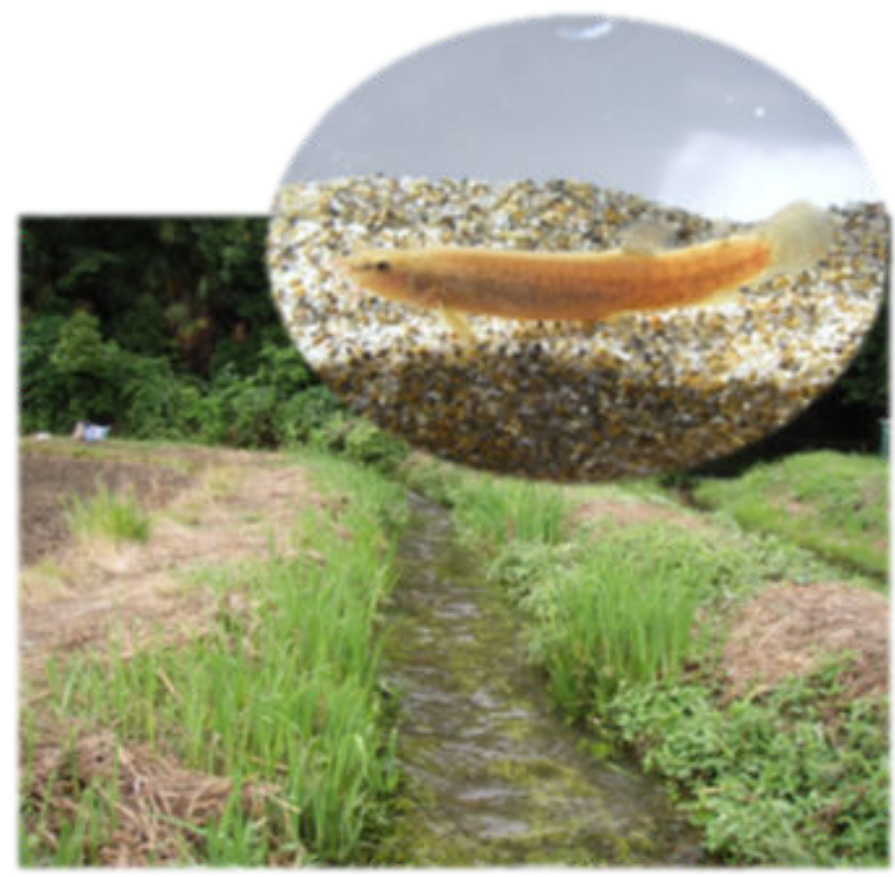

Photo 2. An adult of the Hotoke loach, Lefua echigonia (the above) with approximately $60 \mathrm{~mm}$ in body length and typical earth ditch (the bottom) where the loach inhabits around paddy field (unpublished photo)

In recent years, because importance of ecosystem and biodiversity in rural areas has been deeply realized, various research activities have been carried out for conserving and recovering populations of the Hotoke loach. Distribution pattern and habitat characteristics of this loach were elucidated in some rural areas [15-18], manners of habitat utilization and migration routes for the species were investigated $[11,12,19,20]$ and techniques of artificial propagation were developed with human chorionic gonadotropin [21-23]. Further, molecular analyses of phylogeography of the Hotoke loach using DNA sequences of mitochondrial genes revealed that populations of the species were evolutionally separated into a total of 7 genetic clades in Japan [24-29].

Unfortunately, there is also another serious concern left in populations of the Hotoke loach. That is, as this loach has experienced, diminishment of population size may often cause to improve not only fragmentation among populations but also inbreeding among individuals. Such populations tend to have distinctly poor genetic diversity, occasionally threatened with extinction [30-33]. Usually, to evaluate genetic diversity including genetic population structure for such populations, polymorphism analysis has been performed using microsatellite loci in nuclear genome [33-35]. Only preliminary investigations, however, were implemented for populations the Hotoke loach [36-38], although microsatellite analyses have been carried out for populations of several endangered species. 
Genetic properties of microsatellite loci are briefed as follows (Fig. 1). These loci are repeating sequences of 2 to 6 base pairs of DNA, for instance CACA..., CTCTCT... and CATCAT... Microsatellites that are typically neutral and co-dominant are used as molecular markers in genetics for kinship, population and other studies, because of often presenting high levels of inter- and intra-specific polymorphism [33-35]. Especially, CA nucleotide repeats appear to be very frequent in human and other genomes and present every few 10,000 to 100,000 base pairs. A repeat size in a locus is treated as an allele and a pair of repeat sizes which are inherited from both of parents is used as genotypes at a locus for a diploid organism. Heterozygous describes a genotype consisting of two different sizes (alleles), while homozygous does it consisting of two identical ones (Fig. 1).

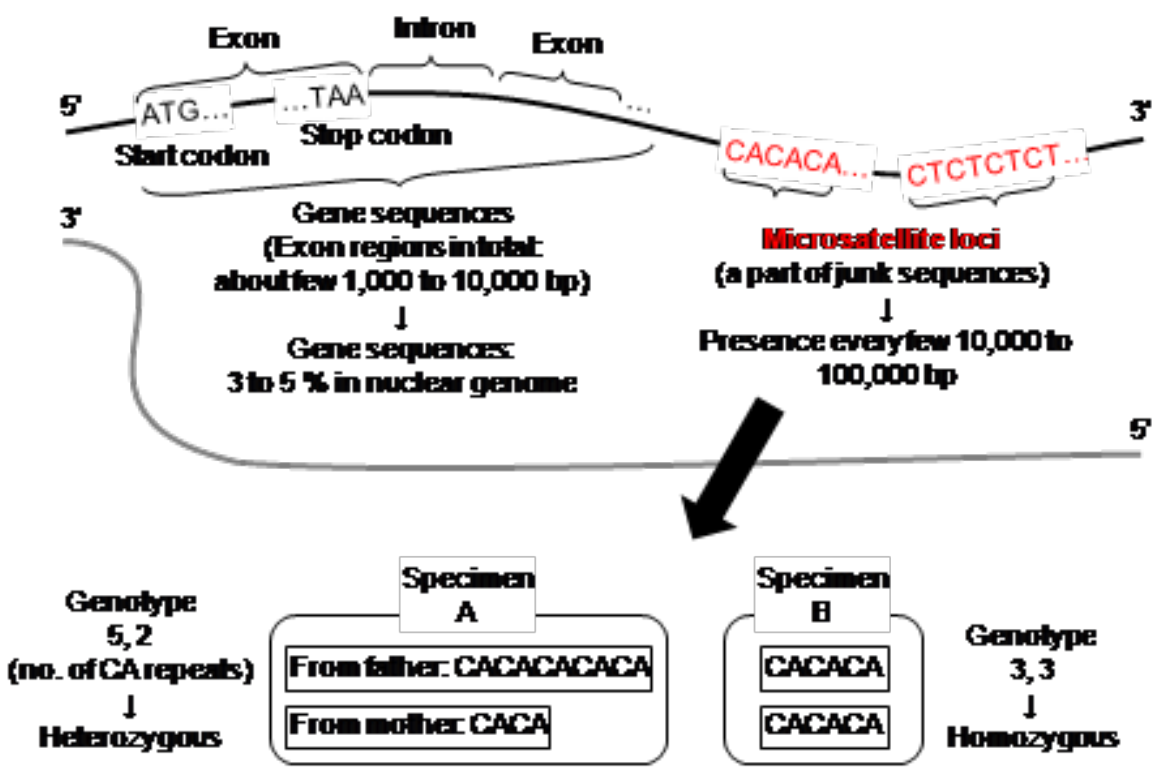

Figure 1. Scheme of microsatellite loci in nuclear genome DNA (unpublished figure)

In this chapter, to detect the existence of the above serious genetic issues, we carried out a series of analysis for genetic diversity and population structure in population of the Hotoke loach (Fig. 2). Novel microsatellite loci applied in this loach were developed and characterized in Section 2. Using these developed loci, genetic diversity and population structure were investigated for populations in the upper Kokai River along with adjacent rivers, the southeast part of Tochigi Prefecture as a case study in Section 3. Technical terms related to population and conservation genetics are often used in the sections; thus, details of meanings of these terms are able to be known by references cited in the end of this chapter. 


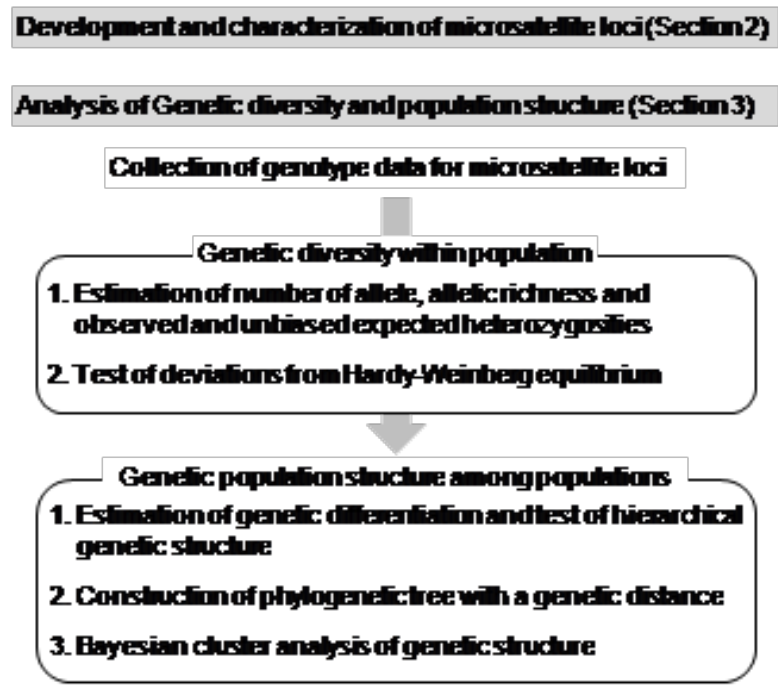

Figure 2. Analysis flow chart of microsatellite loci in this chapter (unpublished figure)

\section{Development and characterization of microsatellite loci}

\subsection{Development of microsatellite loci}

In Section 2, a total of 19 novel microsatellite loci for the Hotoke loach were isolated with an individual obtained in the Shitada R., Chiba Pref. and characterized using 32 individuals collected from the Koise R., Ibaraki Pref. The following development procedure [36] is partially improved based on the latest studies $[39,40]$.

A sample of this loach was collected from an agricultural canal in the Shitada R., Chiba Pref. in 2005 and preserved in $99 \% \mathrm{EtOH}$, and then stored at $-30{ }^{\circ} \mathrm{C}$. Genomic DNA was extracted from single caudal fin clip, approximately $5 \mathrm{~mm} \times 5 \mathrm{~mm}$, using a standard phenol-chloroform procedure [41]. Microsatellite enriched libraries were developed following the previous study [42] with some modifications. Briefly extracted DNA was digested with RsaI (New England Biolabs) and then ligated to SuperSNX linkers (SuperSNX24 Forward: 5'-GTT TAA GGC CTA GCT AGC AGA ATC-3' and SuperSNX24+4P Reverse: 5'-phosphate-GAT TCT GCT AGC TAG GCC TTA AAC AAA A-3'). Linker-ligated DNA was enriched for microsatellites using streptavidin-coated magnetic beads (Dynal) treated with a blocking step [43] and using the pooled biotinylated probes (CA) $)_{12}$ and $(\mathrm{CT})_{12}$.

Recovered DNA was amplified by the polymerase chain reaction (PCR) and PCR products were cloned using a TOPO-TA Cloning Kit (Invitrogen) following the manufacture's protocol. A total of 192 positive clones were sequenced on a 3130xl Genetic Analyzer (Applied Biosystems; $\mathrm{ABI}$ ) using BigDye Terminator kit version $3.1(\mathrm{ABI})$ and resultant sequences were 
proofread for repeat regions using the software DNA BASER version 3.2 (Heracle BioSoft). Oligonucleotide primers (Table 1) were designed in flanking regions of the 19 targeted microsatellite loci using the software DNASIS PRO version 3.0 (Hitachi Software Engineering).

\begin{tabular}{|c|c|c|c|c|}
\hline Locus & Primer sequence $\left(5^{\prime}-3^{\prime}\right)^{a}$ & Repeat motif & Dye & $\begin{array}{c}\text { GenBank } \\
\text { accession no. }\end{array}$ \\
\hline \multirow{2}{*}{ Lec01 } & F: M13-ATC CCT CCC TTC ACC GTC TG & \multirow[b]{2}{*}{$(C A)_{13}$} & \multirow{2}{*}{ 6-FAM } & \multirow{2}{*}{ AB286032 } \\
\hline & R: TCC GAA ACC AGC AGC ACC AC & & & \\
\hline \multirow{2}{*}{ Lec02 } & F: M13-TGT GCT GTA GGA TTG CTT GAG C & \multirow{2}{*}{$(\mathrm{CA})_{30} \mathrm{AA}(\mathrm{CA})_{5}$} & \multirow{2}{*}{ VIC } & \multirow{2}{*}{ AB286033 } \\
\hline & R: ATG TCA GAG GCT GAT GG GAT AC & & & \\
\hline \multirow{2}{*}{ Lec03 } & F: M13-CGT CCA CCA GCC TTA CGA AC & \multirow{2}{*}{$(\mathrm{CA})_{14} \mathrm{CG}(\mathrm{CA})_{3}$} & \multirow{2}{*}{ 6-FAM } & \multirow{2}{*}{ AB286034 } \\
\hline & R: TGA CGC TCA GTA GTC GGA CC & & & \\
\hline \multirow{2}{*}{ Lec04 } & F: M13-GCA CTG CTG ATG ACA ATC ATT G & \multirow{2}{*}{$(\mathrm{GA})_{29}$} & \multirow{2}{*}{ 6-FAM } & \multirow{2}{*}{ AB286035 } \\
\hline & R: GCT TTG GGT TAG AAC ATC AGT G & & & \\
\hline \multirow{2}{*}{ Lec05 } & F: M13-TGT CTG CTG TGA TGA TGA CAT C & \multirow{2}{*}{$(\mathrm{GT})_{13}$} & \multirow{2}{*}{ NED } & \multirow{2}{*}{ AB286036 } \\
\hline & R: CTC ACA GCA CTA TTC ACT GAT G & & & \\
\hline \multirow{2}{*}{ Lec06 } & F: M13-CCG TGT CTG TTT TGC TTT CTC & \multirow{2}{*}{$(\mathrm{CT})_{10}$} & \multirow{2}{*}{ PET } & \multirow{2}{*}{ AB286037 } \\
\hline & R: CTC CCT TCA CAA AGT AAC TGG & & & \\
\hline \multirow{2}{*}{ Lec07 } & F: M13-TGT GAA GAA ACC TGA ACA CGC & \multirow{2}{*}{$(\mathrm{CT})_{7}(\mathrm{GT})_{11}$} & \multirow{2}{*}{ NED } & \\
\hline & R: ATT CTG TGT CCC TGA ACA CAC & & & AB286038 \\
\hline lec08 & F: M13-GAC GCA ACA ATC TCA GGG TC & $(\mathrm{GA})_{5} \mathrm{AA}(\mathrm{GA})_{8}$ & 6-FAM & $A B>86039$ \\
\hline Lecvo & R: ACA GGA CCA AGT GGA CTC TC & $\mathrm{AA}(\mathrm{GA})_{17}$ & (2) fivi & HULO \\
\hline Lec09 & F: M13-GGG GAT AGT GGA GAT GGG TG & (GA) & PET & $A B 286040$ \\
\hline & R: TTC ATC CCT CTT CCG CCC AC & $(G A)_{14}$ & PLI & $A D \angle 00040$ \\
\hline Lec10 & F: M13-GGT TGG CAA TGC CAG CAA TG & (GT) & $6-\mathrm{F} M \mathrm{M}$ & $\triangle P 286041$ \\
\hline Lecio & R: TGC TTT ACC AAG GTG ACG GC & $(\mathrm{G} /)_{7}$ & b-FAMI & AB286041 \\
\hline Lec11 & 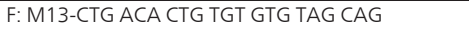 & (GT) & NED & $A B 286042$ \\
\hline & R: GGT TTC ACC TGG TCC ATA CAC & & & \\
\hline $1 e c 12$ & F: M13-GGC ACC AAA GGC AGA TTT TAC & $(\mathrm{CT})_{14} \mathrm{CA}(\mathrm{CT})_{2}$ & $V I C$ & $A B 286043$ \\
\hline Lecis & R: AGA GTG TGA GAT TAT GGC AGC & $(\mathrm{CA})_{6}$ & 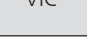 & AD 200045 \\
\hline $1 e c 13$ & F: M13-GAC GCC ACG ACA AGA CGA AC & (CT) & NED & $A B 286044$ \\
\hline Lecis & R: TAT GTG TGG AGG GGG GTG AG & $(\mathrm{Cl})_{21}$ & TNED & $A B \angle 86044$ \\
\hline Lec14 & F: M13-ATT AGG AGC ATT ACC CAA CAG C & $(\mathrm{GT})_{-}$ & NED & $A B 286045$ \\
\hline & R: CAA AGG AAG CAA AAA CAA GGG C & $(\mathrm{Gl})_{7}$ & NED & $A B \angle 86045$ \\
\hline Lec15 & F: M13-GAG CAA GAG GTG TGT GCT TC & $(G T)_{n}$ & PET & AB286046 \\
\hline & R: TGC TGG TTC ACG CTC TAC AC & (01/11 & & \\
\hline lec16 & F: M13-CAC ACT AAC ACT TCT CCA GCG & (CA) & $6-$ EAM & $\triangle P 286047$ \\
\hline Lec io & R: CAC AGT GAC CAA AGT CAC CAG & $(\mathrm{CA}) 10$ & O-FAIVI & $A B \angle 00041$ \\
\hline Lec17 & F: M13-GTC CCC ATA AAA CAG GAA ACC C & $(\mathrm{GT})_{7} \mathrm{GCGTGG}$ & VIC & AB286048 \\
\hline Lecis & R: GAC TAT TGA GTG AGT GCC ACA C & $(G T)_{5}$ & VIC & $A B \angle 86048$ \\
\hline lec18 & F: M13-CGA CCA TCT TCT GGG GTT ACG & (GT) & NFD & AB439725 \\
\hline Letio & R: CCT CGG ATG GGC TAA ATG ACC & $101 / 9$ & TVLO & 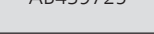 \\
\hline Lec19 & F: M13-CTG TGT GTG GGT GTA TCT GAA C & (GT) & PET & AB439726 \\
\hline & R: AAA GTG GCT CTT CTT CTG CTG G & 1016 & & \\
\hline
\end{tabular}

a Sequence of the M13 tails on forward primers: GCC AGT CAC GAC GTT GTA

Table 1. Characterization of 19 polymorphic microsatellite loci for 32 individuals of the Hotoke loach. Loci with gray color were used in analysis of genetic diversity and population structure in Section 3. (Modified from one of previous study [36]) 


\subsection{Characterization of microsatellite loci}

Each microsatellite locus was characterized for polymorphisms among 32 individuals obtained the Koise R., Ibaraki Pref. in 2006. DNA of the individuals was extracted using an automated DNA isolation system (GENE PREP STAR PI-80X, KURABO) following the manufacturer's instructions. PCR amplifications were performed on the 32 DNA extracts across all loci using $10 \mu \mathrm{l}$ reaction volumes containing approximately $10 \mathrm{ng}$ DNA template, $0.5 \mathrm{U}$ Taq DNA polymerase (BIOTAQ, Bioline), $1 \times \mathrm{NH}_{4}$ buffer (BIOTAQ), $2.5 \mathrm{mM} \mathrm{MgCl}$, $0.25 \mathrm{mM}$ each dNTP, $0.03 \mu \mathrm{M}$ M13-tailed forward primer, $0.25 \mu \mathrm{M}$ reverse primer and 0.25 $\mu \mathrm{M}$ labeled M13 primer (5'-GCC AGT CAC GAC GTT GTA-3') [44]. The M13 primer was labeled at the 5' end with 6-FAM, VIC, NED or PET fluorescent dyes (ABI, Table 1).

Thermal profiles on iCycler and C1000 (both of Bio-Rad) of thermal cyclers were as follows. Initial denaturation at $94^{\circ} \mathrm{C}$ for 2 min was followed by 40 cycles of denaturation at $94^{\circ} \mathrm{C}$ for $15 \mathrm{~s}$, annealing at $56^{\circ} \mathrm{C}$ for $15 \mathrm{~s}$ and extension at $72^{\circ} \mathrm{C}$ for $30 \mathrm{~s}$. A single final extension at $72^{\circ} \mathrm{C}$ was done for $30 \mathrm{~min}$. PCR products were resolved on a $3130 x \mathrm{l}$ Genetic Analyser with GeneScan 500 LIZ size standard (ABI). Electropherograms were analyzed with the software GENEMAPPER version 4.0 (ABI).

Measures of genetic diversity, tests for deviations from Hardy-Weinberg equilibrium (HWE) and estimates of linkage disequilibrium (LD) between loci were calculated using the software GENEPOP on the web version 4.0.10 [45]. The possible presence of null alleles was assessed with the software MICRO-CHECKER version 2.2.3 [46].

All the 19 loci were polymorphic (Table 1). The number of observed alleles per locus ranged from 2 to 9 . The observed heterozygosity ranged from 0.125 to 0.844 , while the expected heterozygosity varied from 0.148 to 0.876 . No significant deviations from HWE or signs of LD were observed after sequential Bonferroni correction with the significant level at 0.05 [47] and there was no evidence of null alleles in any of the tested loci. Consequently, the high level of polymorphisms observed in these microsatellite loci may have to support future investigations to improve our knowledge of the genetic differentiation and genetic structure of populations of the Hotoke loach.

\section{Analysis of genetic diversity and population structure}

\subsection{Study sites}

In Section 3, genetic diversity and population structure of populations of the Hotoke loach in the upper Kokai R. including 4 adjacent rivers, the southeast part of Tochigi Pref. (Fig. 3) was detailed using the microsatellite loci developed in Section 2 (Table 1). As mentioned in Section 1, populations of the Hotoke loach have been often diminished and isolated by land consolidation projects in rural areas. Therefore it appears difficult to find populations distributed with a certain area. However, rich biota still continues to exist in the upper Kokai R. due to delay of land consolidation. This area sounds attractive for field scientists, and then their some activities were carried out to conserve and recover such a sound rural ecosystem 
[48-52]. According to the results of these studies [48, 49], the populations of the Hotoke loach tended to be distributed in the upper zone of hill-bottom valleys in this area and also a negative correlation was observed between the population size and water temperature.

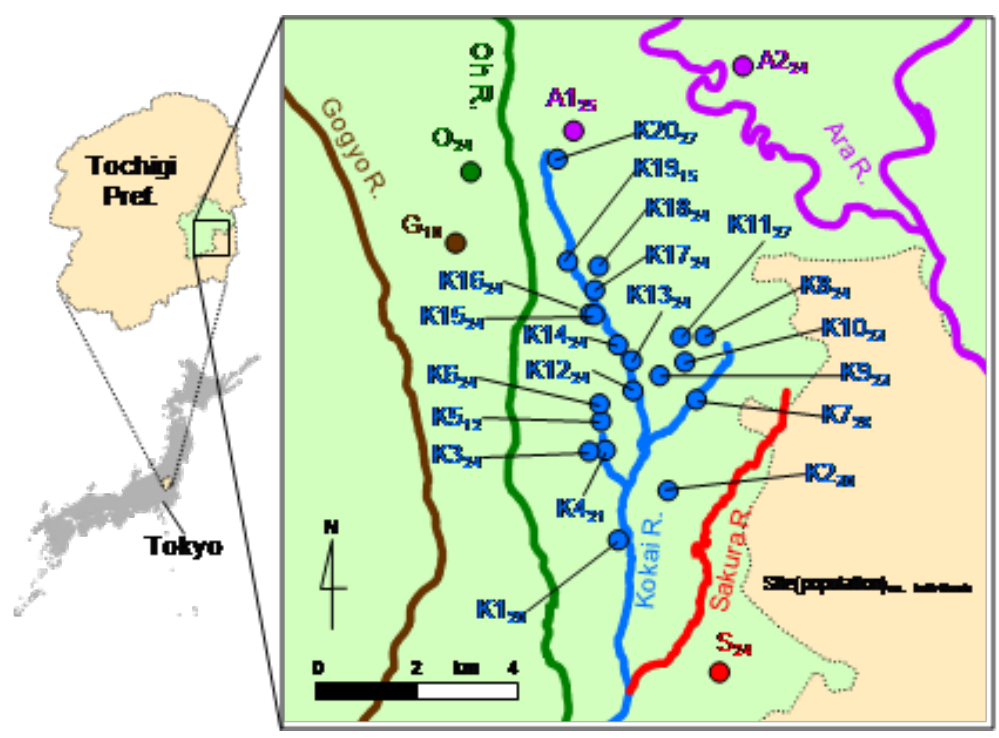

Figure 3. Collection sites for individuals of populations of the Hotoke loach in the upper of Kokai River (K1 to K20) along with adjacent the Oh, Sakura, Gogyo and Ara Rivers (O, S, G and A1, A2, respectively), the southeast part of Tochigi Prefecture (unpublished figure).

Considering such spatial distribution patterns in the previous studies $[48,49]$ and geographical conditions in this area, a total of 20 sites were established to collect individuals of the populations in the upper Kokai R. (K1 to K20 in Fig. 3). Additionally 5 collection sites of adjacent 4 rivers that are the Oh, Sakura, Gogyo and Ara (O, S, G and A1, A2, respectively in Fig. 3) were decided to compare with the populations of the Kokai R.

\subsection{Sample collection}

Sample collections in each site (Fig. 3) were performed using hand nets with reticulation at 2 $\mathrm{mm}$, flame width at 30 to $40 \mathrm{~cm}$ in August 2007 to June 2008 (Photo 4). 10 to 24 individuals (a total of 573 individuals) of each population were collected in earth canals and ditches with water depth of 2 to $24 \mathrm{~cm}$, water width of 15 to $110 \mathrm{~cm}$, flow velocity of 5 to $25 \mathrm{~cm} / \mathrm{s}$ and substrates consisting of silts, sands and gravels. There were no rain during the sample collections and a part of the caudal fin $(3 \mathrm{~mm} \times 3 \mathrm{~mm})$ of each individual was removed and preserved in $99.5 \% \mathrm{EtOH}$ at the sites, and then all individuals were immediately released alive. The preserved caudal fins were kept at $-30{ }^{\circ} \mathrm{C}$ and the mean \pm standard deviation in body length for all individuals was $46 \pm 11 \mathrm{~mm}$. 


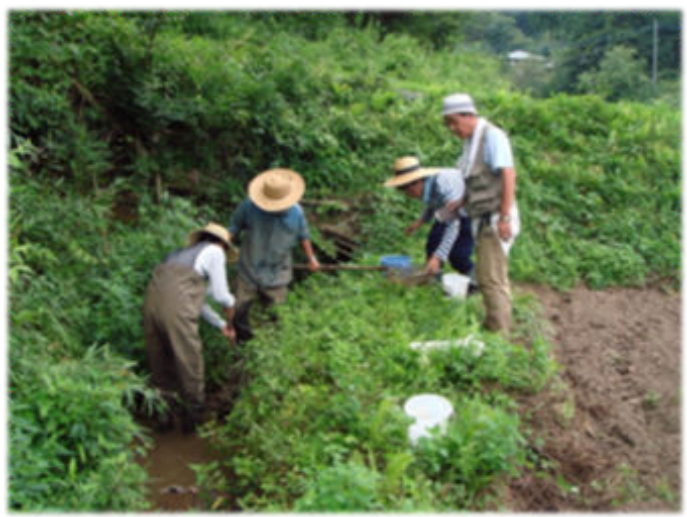

Photo 3. Collection of individuals of the Hotoke loach in an earth ditch at the site K9 in the Kokai River (unpublished photo)

\subsection{DNA chemical analysis}

Total genomic DNA from the preserved caudal fins of each individual was extracted using an automated DNA isolation system following the manufacturer's instructions, and kept at $4{ }^{\circ} \mathrm{C}$ after being diluted to $10 \mathrm{ng} / \mu \mathrm{l}$.

The microsatellite DNA analysis were performed using the following 11 loci that are Lec01, Lec05, Lec06, Lec08, Lec12, Lec14, Lec15, Lec16, Lec17, Lec18 and Lec19 with gray color in Table 1 . These loci were confirmed to be appropriate for investigating the populations in the Kokai R. in the preliminary studies $[37,38]$. In accordance with the procedure in Section 2, microsatellite amplification with PCR on iCycler and C1000 of thermal cyclers was conducted in $10 \mu \mathrm{l}$ reaction volumes containing approximately $10 \mathrm{ng}$ DNA templates. PCR products were electrophoresed on a 3130xl Genetic Analyzer with GeneScan 500 LIZ of size markers and the electrophoregrams were analyzed with the GENEMAPPER. Consequently genotype data composed of a pair of fragment sizes, which are inherited from both of parents and depends on length of repeat motif, was obtained for each individual in a PCR product of a locus. All genotype data were compiled in the software THE EXCEL MICROSATELLITE TOOLKIT [53].

\subsection{DNA data analysis}

\subsubsection{Genetic diversity within population}

The genetic diversity within the populations of the Hotoke loach in each collection site was evaluated with the genotype data of the 11 loci for all individuals. The number of allele $\left(N_{A}\right)$ and allelic richness $\left(A_{r}\right)$ [54], where bias caused by population size (the number of individuals) is removed from $N_{A}$, were estimated using the software GENALEX version 6.41 [55] and FSTAT version 2.9.3 [56], respectively. Differences of $N_{A}$ and $A_{r}$ among the populations were 
tested by one-way analysis of variance (ANOVA) using the software EKUSERU-TOUKEI 2010 (Social Survey Research Information Co., Ltd.).

The observed and unbiased expected heterozygosities $\left(H_{O}\right.$ and $H_{E}$, respectively) [57] were calculated by GENALEX [55]. The software ARLEQUIN version 3.11 [58] was used to test deviations from Hardy-Weinberg equilibrium with Fisher's exact probability test, which was run through 100,000 iterations using the Markov chain Monte Carlo (MCMC). Significance values $(\alpha=0.05)$ of a multiple test were corrected following the sequential Bonferroni procedure [47]. Significant differences of $H_{O}$ and $H_{E}$ among the populations were detected by one-way ANOVA using EKUSERU-TOUKEI 2010.

\subsubsection{Genetic population structure among populations}

Genetic population structure among the populations in the Kokai R. including 4 adjacent rivers was elucidated with three analytical methods based on the assumption that mutation of alleles in each locus confirmed to an infinite allele model [59, 60].

First, genetic differentiation between the populations was evaluated with classical pairwise $F_{S T}$ statistics [61] using ARLEQUIN [58]. Statistical significance $(\alpha=0.05)$ for values of $F_{S T}$ was tested with applying 10,000 permutations, followed by sequential Bonferroni corrections [47] and these values were graded on four classifications for genetic differentiation in the previous study [62]. An analysis of molecular variance (AMOVA) [63] for $F_{S T}$ was performed to estimate hierarchical genetic structure across the populations. In this AMOVA, the populations were divided into 2 to 6 groups according to geographical condition such as rivers and the distances among collection sites. And then variances among groups, among populations within groups, among individuals within populations and within all individuals were computed for 3 cases of genetic structure using GENALEX [55] with 10,000 permutations.

Second, a phylogenetic tree of a genetic distance $D_{A}[64]$ between the populations was constructed with the neighbor-joining method [65] and the reliability of the obtained phylogenetic tree was evaluated using the aid of 1,000 bootstrap replicates [66]. The software POPULATIONS version 1.2.31 [67] was used to estimate $D_{A}$ and to construct a phylogenetic tree and an appropriate shape of the phylogenetic tree was edited with the software MEGA version 5.05 [68].

Finally, Bayesian cluster analysis [69-73] that has been recently used as a popular method was implemented in the software STRUCTURE version 2.3.3 [70] to circumstantially investigate the occurrence of genetic structure among the populations without the prior identification of populations. Briefly, this analysis allows the inference of the number of genetically homogeneous clusters $(\mathrm{K})$ that are implicitly genetic populations from individual genotypes at multiple loci and also assignment probability (Q) of individuals to each genetic cluster. The admixture model and correlated allele frequencies model were used along with LOCPRIOR model [74] and the software was run with 20 repetitions of 500,000 iterations of MCMC, following a burn-in of 500,000 iterations at K of 1 to 10.

The most likely number of genetic clusters was evaluated using the rate of change in the log probability between the values of successive K [75]. Distribution of the values of $Q$ across 
runs for each cluster were organized using the software STRUCTURE HARVESTER web version 0.6.92 [76] and then summarized using the software CLUMPP [77]. When individuals had the values of $Q$ more than 0.7 , they were assigned to be members of that particular cluster in this study. And also K usually appears to show the genetic structure at the uppermost hierarchical level [75]. Therefore, when a particular cluster was formed by some populations, additional analysis of each cluster was performed to investigate the detailed genetic structures after the first analysis.

\subsection{Results and discussions}

\subsubsection{Genetic diversity within populations}

All the 11 microsatellite loci were moderate to highly polymorphic, with the number of alleles $\left(N_{A}\right)$ and observed and unbiased heterozygosities $\left(H_{O}\right.$ and $H_{E}$, respectively) per locus for all individuals ranging from 2 (Lec19) to 40 (Lec06) and from 0.147 (Lec17 and Lec19) to 0.846 (Lec05) and from 0.155 (Lec17) and 0.915 (Lec08), respectively. Such a polymorphic level observed in these loci indicated to be beneficial to investigating genetic characteristics of populations in detail.

Means of $N_{A}$ per locus in the populations varies from 4.5 (Population A2, hereafter Pop A2) to 8.0 (Pop K11). Allele richness $\left(A_{r}\right)$ per locus was standardized by the minimum size of the population (10 individuals of Pop G) and its means per locus varied from 3.7 (Pop A2) to 5.6 (Pop K11) among populations (Fig. 4). The one-way analysis of variance (ANOVA) showed that significant differences of the means of both $N_{A}$ and $A_{r}$ were not confirmed among populations $\left(F_{24}\right.$, ${ }_{250}=0.641, M_{S E}=11.937, p>0.05$ for $N_{A}$ and $F_{24,250}=0.459, M_{S E}=4.803, p>0.05$ for $A_{r}$ ).

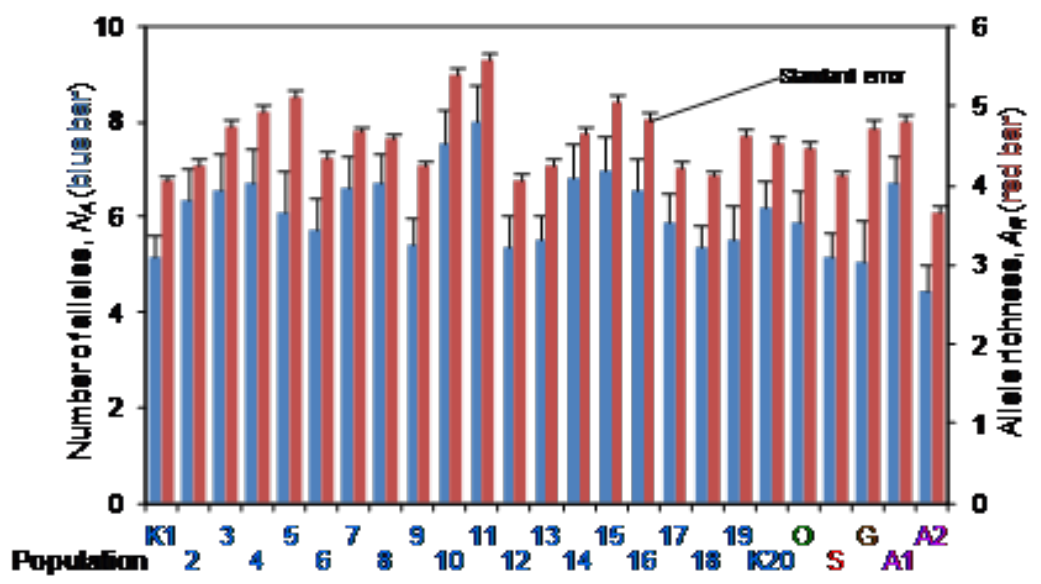

Figure 4. Means and standard errors of the number of alleles $\left(N_{A}\right)$ and allelic richness $\left(A_{r}\right)$ per locus in the populations (unpublished figure). $A_{r}$ was standardized by the minimum size of the population (10 individuals of Population $\mathrm{G}$ ) and there were no significant differences among the populations for both $N_{A}$ and $A_{R}(p>0.05)$. 
Means of the observed and unbiased expected heterozygosities $\left(H_{O}\right.$ and $H_{E}$, respectively) per locus across all population ranged from 0.418 (Pop A2) to 0.669 (Pop K11) and from 0.507 (Pop A2) to 0.674 (Pop K11), respectively (Fig. 5). Significant departures from the HardyWeinberg equilibrium (HWE) were not observed in all the populations. This result indicated that the populations could be applied to the following analyses of genetic population structure, because most analyses are often performed under the assumption that population conforms to HWE. The results of one-way ANOVA showed that there were no significant of the differences among the populations for both $H_{O}$ and $H_{E}\left(F_{24,250}=0.377, M_{S E}=0.090, p>0.05\right.$ for $H_{O}$ and $F_{24,250}=0.207, M_{S E}=0.079, p>0.05$ for $\left.H_{E}\right)$.

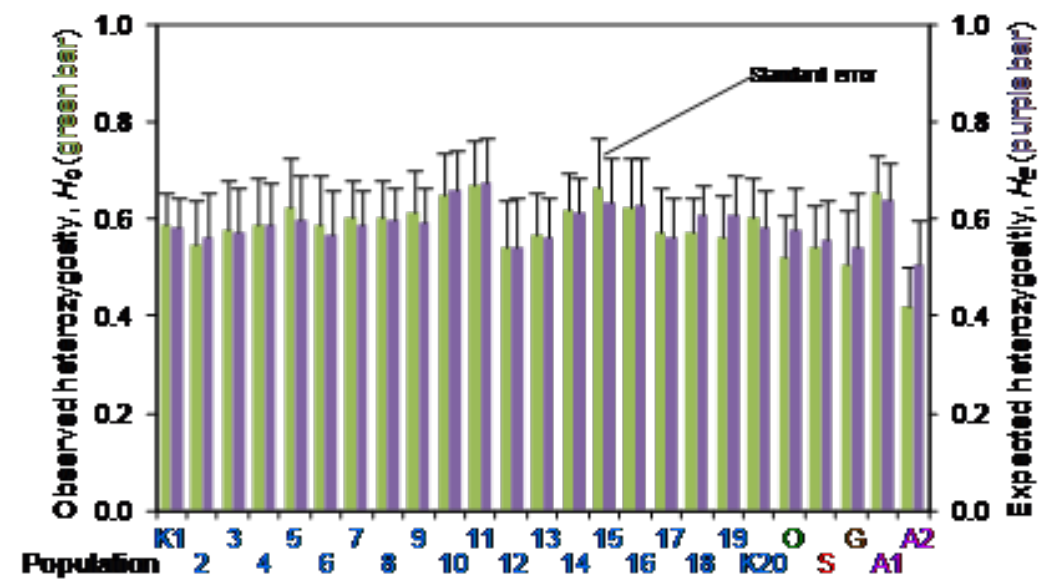

Figure 5. Means and standard errors of the observed and unbiased expected heterozygosities $\left(H_{O}\right.$ and $H_{E}$, respectively) per locus in the populations (unpublished figure). There were no significant differences among the populations for both $H_{O}$ and $H_{E}(p>0.05)$.

Genetic diversity of the populations appeared not to degrade. Generally, when population size is small, inbreeding among individuals appears to progressively occur in a population [30-33] as mentioned in Section 1. It has been observed that such populations had low values of $N_{A}, H_{O}$ and $H_{E}$ [33]. For instance, means of $N_{A}$ per locus for the Ethiopian wolf, Canis simensis, the Mauritius kestrel, Falco punctatus and the Northern hairy-nosed wombat, Lasiorhinus krefftii which are designated as worldwide endangered species, were only 2.4, 1.4 and 2.1, respectively. Means of $H_{E}$ for the Ethiopian wolf, the Mauritius kestrel and the Northern hairy-nosed wombat were also $0.21,0.10$ and 0.32 , respectively [78]. But then, values of representatively common freshwater fish species inhabiting agricultural canals and ditches in rural area, Japan such as the Dojo loach, the Field gudgeon, Gnathopogon elongates elongatus and the Amur goby (orange type), Rhinogobius sp. OR ranged from 3.3 to 17.7 (both of the Amur goby) for means of $N_{A}$ per locus and from 0.463 (the Dojoloach) to 0.905 (the Field gudgeon) for means of $H_{E}$ per locus [79-81].

Comparing with these values for the endangered and common species, the means of $N_{A}$ and $H_{E}$ per locus ( 4.5 to 8.0 and 0.507 to 0.674 , respectively) observed in the populations indicated to be 
in relatively moderate level. Hence, a serious concern for genetic diversity could not occur in the populations at present. However, there are no confident that such a level of genetic diversity would be sustaining in the future. Monitoring genetic diversity may need including ordinary biological investigation such as an estimation of size and age composition of populations.

\subsubsection{Genetic population structure inferred from $F_{S T}$}

The lowest and highest values of $F_{S T}$ were observed between Pops K15 \& K16 and between Pops K18 \& A2 ( $F_{S T}=0.008$ and 0.246 , respectively, Fig. 6). The permutation test showed that all the $F_{S T}$ were significantly different from zero $(p>0.05)$, except the lowest $F_{S T}$ between Pops K15 \& K16 after sequential Bonferroni corrections [47].

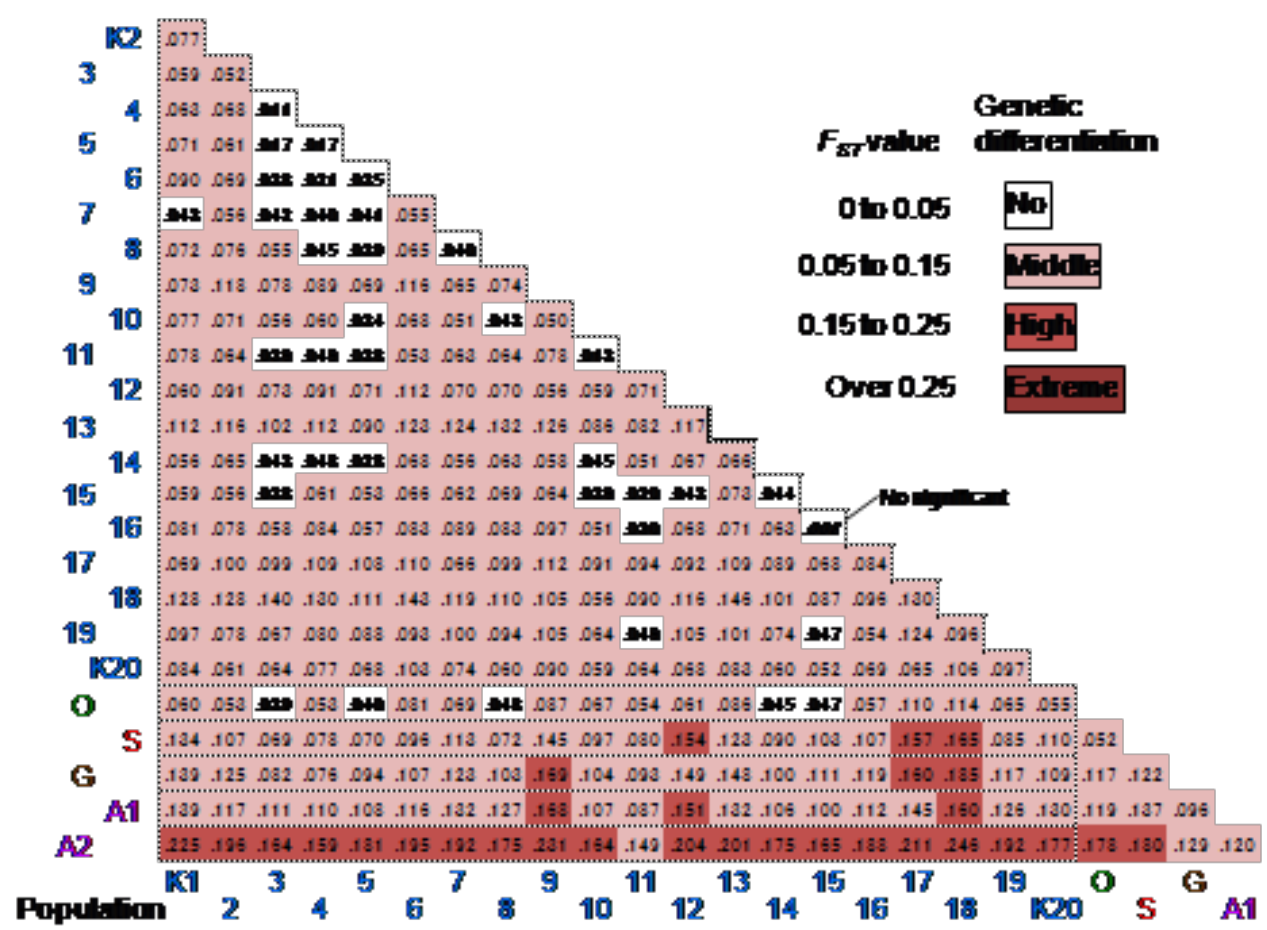

Figure 6. Values of pairwise $F_{S T}$ between the populations and their grades of genetic differentiation composed of four classifications (unpublished figure). All the value of $F_{S T}$ were significantly different from zero $(p>0.05)$, except between Populations K15 \& K16 $\left(F_{S T}=0.008\right)$. Four classifications of genetic differentiation derive from the previous study [62].

Values of $F_{S T}$ were graded on four classifications for genetic differentiation based on the previous study [62]. These classifications imply no, middle, high and extreme genetic differentiation when $F_{S T}$ ranges from 0 to 0.05 , from 0.05 to 0.15 , from 0.15 to 0.25 and over 0.25 . Applying this grade, $20.3 \%$ of the $F_{S T}$ (32/190) between the populations within the Kokai R. (Pops K1 to K20) 
were classified into no genetic differentiation and a part of such populations tended to be close located each other (Fig. 6). The remaining $F_{S T}$ within the Kokai R. were classified into middle genetic differentiation. Between the populations in the Kokai $\mathrm{R}$. and adjacent 4 rivers (Pops $\mathrm{O}$ to A2), their $F_{S T}$ showed middle to high genetic differentiation, although the $F_{S T}$ between the populations in the Kokai and Oh Rs were partially no differentiation.

The analysis of molecular variance (AMOVA) was implemented for the following Cases I to III, among which the number of groups and composition of the populations in groups differed. In Case I, the populations of the Kokai R. (K1 to K20) and 4 adjacent rivers (Pops O to A2) were divided into Group Casel $_{1}$ and 2, respectively. In Case II, Group CaseII $_{1} 1$ was formed by the populations of the Kokai, Oh and Sakura Rs (Pops K1 to S) and Group caseII $_{2}$, 3 and 4 were formed by 3 remaining populations of 2 rivers (Pops G, A1 and A2). There were groups Group CaseIII $_{1} 1$ to 6 composed of the populations of the Kokai (Pops K1 to K20), Oh (Pop O), Sakura (Pop S), Gogyo (Pop G), one Ara (Pop A1) and another Ara (Pop A2) R. in CaseIII.

Significant genetic differentiations were observed at all hierarchical levels in all cases $(p<$ 0.01 , Table 2). The largest genetic variance in all variances was found at the level of within individuals in each case (from $82.5 \%$ in Case II to $86.0 \%$ in Case I). The genetic variances at the levels of among groups and among populations within groups accounted for $2.8 \%$ in Case I to $7.3 \%$ in Case II and $6.9 \%$ in Case II and III to $7.9 \%$ in Case I, respectively (Table 2).

\begin{tabular}{|c|c|c|c|c|c|c|}
\hline \multirow{2}{*}{$\begin{array}{c}\text { Case } \\
\text { (no. groups) }\end{array}$} & \multirow[b]{2}{*}{ Statistic } & \multicolumn{5}{|c|}{ Hierarchy } \\
\hline & & $\begin{array}{c}\text { Among } \\
\text { groups (A) }\end{array}$ & $\begin{array}{c}\text { Among pops } \\
\text { within groups (B) }\end{array}$ & $\begin{array}{c}\text { Among inds } \\
\text { within pops (C) }\end{array}$ & $\begin{array}{l}\text { Within } \\
\text { inds (D) }\end{array}$ & $\begin{array}{c}\text { Total } \\
\text { (E) }\end{array}$ \\
\hline \multirow{5}{*}{ I (2) } & d.f. & 1 & 23 & 548 & 573 & 1145 \\
\hline & MS & 52.5 & 16.8 & 3.4 & 3.2 & \\
\hline & Var comp & 0.102 & 0.291 & 0.124 & 3.184 & 3.702 \\
\hline & $\%$ of var & 2.76 & 7.87 & 3.35 & 86.01 & 100.00 \\
\hline & $F$ & $0.028^{a}$ & $0.081^{b}$ & $0.106^{c}$ & $0.038^{d}$ & $0.140^{\mathrm{e}}$ \\
\hline \multirow{5}{*}{ II (4) } & d.f. & 3 & 21 & 548 & 573 & 1145 \\
\hline & MS & 34.6 & 15.9 & 3.4 & 3.2 & \\
\hline & Var comp & 0.282 & 0.267 & 0.124 & 3.184 & 3.858 \\
\hline & $\%$ of var & 7.32 & 6.93 & 3.22 & 82.53 & 100.00 \\
\hline & $F$ & 0.073 & 0.075 & 0.142 & 0.038 & 0.175 \\
\hline \multirow{5}{*}{ III (6) } & d.f. & 5 & 19 & 548 & 573 & 1145 \\
\hline & MS & 28.5 & 15.6 & 3.4 & 3.2 & \\
\hline & Var comp & 0.183 & 0.260 & 0.124 & 3.184 & 3.752 \\
\hline & $\%$ of var & 4.88 & 6.94 & 3.31 & 84.86 & 100.00 \\
\hline & $F$ & 0.049 & 0.073 & 0.118 & 0.038 & 0.151 \\
\hline
\end{tabular}

Table 2. Results of analysis of molecular variance (AMOVA) for three Cases I, II and III (unpublished table). Compositions of the populations in groups for Case I to III are referred in the text. Genetic differentiations were significant at all hierarchical levels for each case $(p<0.01)$. 
Genetic differentiation between the populations was significantly inferred from the analysis of $F_{S T}$ and its relevant AMOVA. Geographical condition such as river and the distances among locations appeared to relate to degree of the genetic differentiation as illustrated in the previous studies [37, 38, 82-84]. However, only a part of genetic population structure could be indicated in this analysis, because the proportions of the genetic variances at the level of among groups were relatively low (2.8 to $7.3 \%$ of among groups in Table 2 ). Investigating schematically and visually genetic structure may have to be implemented as further analysis as commented in the previous study [74].

\subsubsection{Genetic population structure inferred from phylogentic tree}

The calculated genetic distance $D_{A}$ between the populations ranged from 0.073 (between Pops K15 \& K16) to 0.99 (between Pops K6 \& A2). In this phylogenetic tree of $D_{A}$ using the neighborjoining method [65] (Fig. 7), there was a few of highly significant divergences of population with the bootstrap probabilities over $90 \%$ (e.g. 98 \% between Pops K15 \& K16, 93 \% between Pops K10 \& K11); while the probabilities left were less than $50 \%$ on most divergences. But, the topology of the phylogenetic tree displayed that there were 4 distinct groups, Group Tree $_{1} 1$ to 4 despite weak condition of the statistical support. Both Group Tree $_{1}$ and 2 consisted of 3 populations of the Gogyo and Ara Rs (Pops G, A1 and A2) and of the Kokai, Oh and Sakura Rs (Pops K8, O and S), respectively. Group ${ }_{\text {Tree }} 3$ consisted of 7 populations collected in the lower part of the Kokai R. (Pops K1 to K7), while Group Tree $_{4} 4$ were formed by the 12 remaining populations coming from the middle and upper part of the Kokai R. (Pops K9 to K20).

The schematic genetic structure of the populations was showed by constructing the phylogenetic tree (Fig. 7). Including the results of the above $F_{S T}$ analysis and AMOVA, the existence of 2 genetic populations that related to Group Tree $_{3}$ and 4 was indicated in the populations within the Kokai R., but these groups were statistically cryptic. It could be expected that characterization of admixture of gene flow and migrants among the populations was displayed by detailing structures of such cryptic genetic populations.

\subsubsection{Genetic structure among populations inferred from Bayesian cluster analysis}

The Bayesian clustering analysis supported the occurrence of two defined genetic clusters, Clusters A and B in the uppermost hierarchical level (Fig. 8). By accounting for the number of individuals with more than $70 \%$ of assignment probability (Q) to each cluster, $98.66 \%$ of all individuals (507/514 individuals) in the populations from the Kokai, Oh and Sakura Rs (Pops K1 to S) were assigned to Cluster A. And also, $91.5 \%$ of the remaining individuals (54/59 individuals) in the populations from the Gogyo and Ara Rs (Pops G to A2) were assigned to Cluster B (Fig. 8).

Further clustering analysis were performed to assign the populations in Clusters A and B to genetic clusters in the second hierarchical level. Applying the same procedure in the first analysis, the appropriate $\mathrm{K}$ were 2 in both analyses. According to the values of $\mathrm{Q}$ of the individuals, they were assigned to one of Clusters I, II or admixture of Cluster I \& II in the analysis of Cluster A and Clusters III or IV in the analyses of Cluster B. 


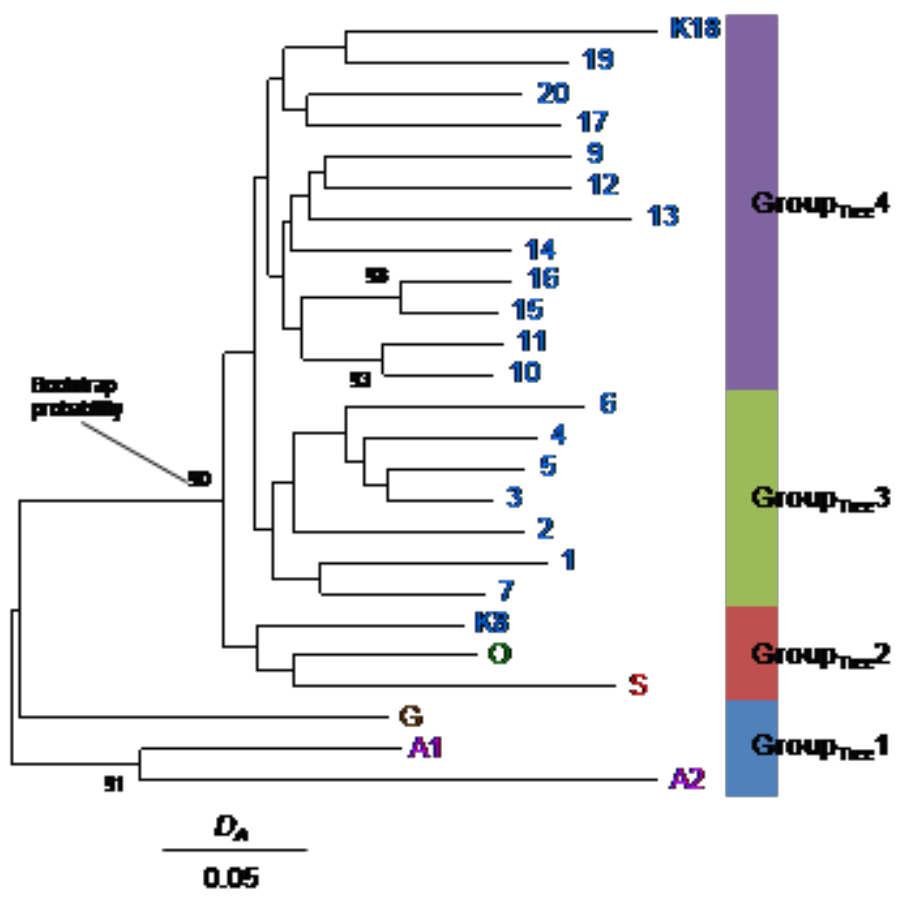

Figure 7. Phylogenetic tree of $D_{A}$ for the populations with neighbour-joining method (unpublished figure) 


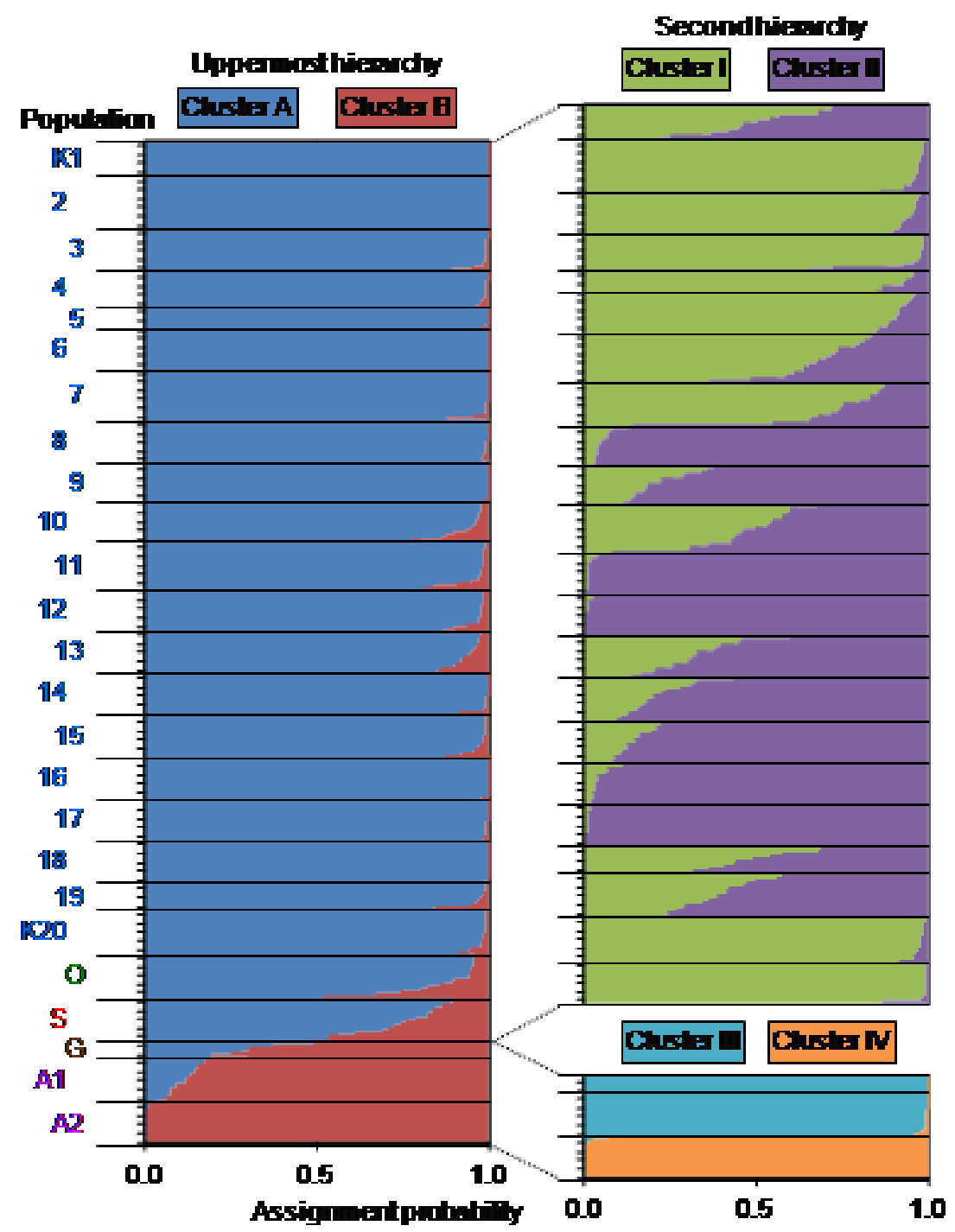

Figure 8. Structures of genetic clusters in the populations inferred by the Bayesian analysis (unpublished figure). Clusters A \& B and I to IV imply the genetic populations at uppermost and second hierarchical levels, respectively. Each individual is represented by a horizontal line fragmented by assignment probabilities to the genetic clusters.

In the analysis of Cluster A, 77.0 to $98.6 \%$ of individuals of Pops $\mathrm{K} 2$ to K6, K8, O and S (a total of 8 populations) in the Kokai, Oh and Sakura Rs were assigned to members of Cluster I (Fig. 8). Considering the geographical locations of the populations as performed in the previous studies [85-88], Cluster I mainly indicated to be the genetic population of the lower 
part of the Kokai including the Oh and Sakura Rs (Fig. 9). 77.4 to $99.0 \%$ of individuals of Pops K9, 10, 12, 13, 15 to 18 (a total of 8 populations) in the Kokai occupied members of Cluster II. Cluster II also implied to be the genetic population of the middle and upper parts of the Kokai R. The remaining individuals of Pops K1, K7, K11, K14, K19 and K20 (a total of 6 populations) in the Kokai R. were mainly classified into members of admixtures of Clusters I \& II. In the analysis of Cluster B, almost all individuals (more than $99.1 \%$ ) of Pops G and A1 in the Gogyo and Ara Rs. and Pop A2 in the Ara R. were assigned to Clusters III and IV, respectively (Fig. 8). Cluster III and IV reflected the genetic populations of the Gogyo and one of Ara R. and another of the Ara R., respectively (Fig. 9).

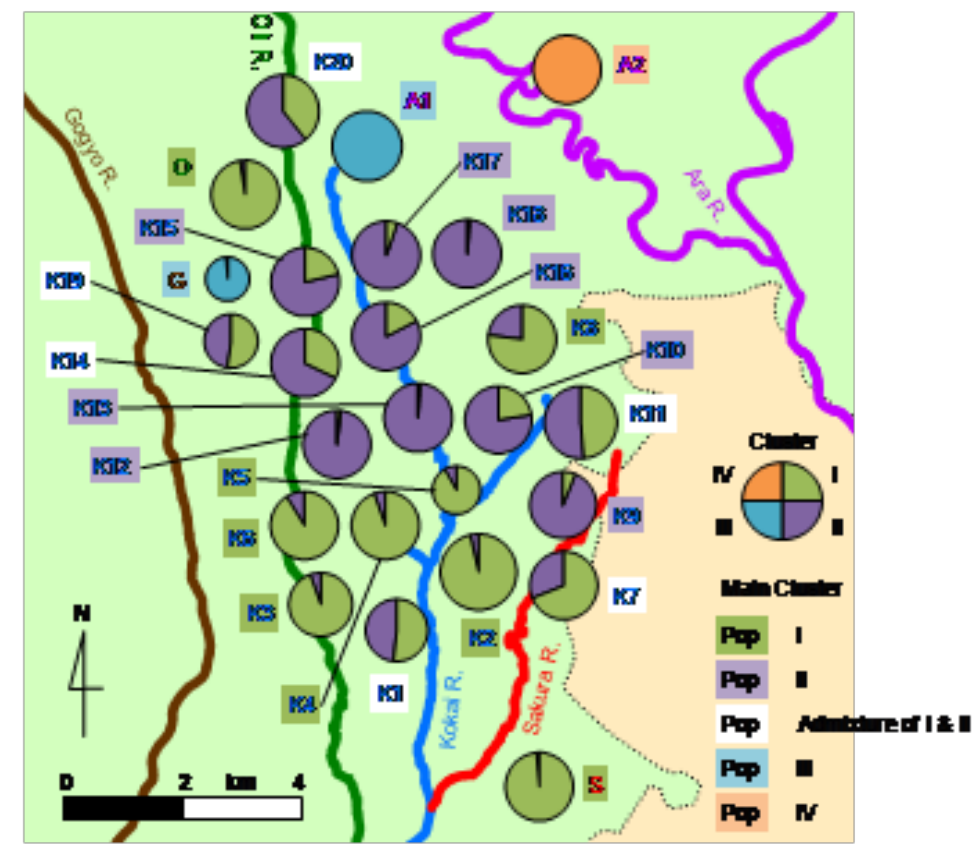

Figure 9. Spatial distribution and composition of genetic clusters in populations (unpublished figure). Size of circle reflects that of population.

Consequently the four genetic populations (Clusters I to IV) and a mixed genetic population (admixture of Cluster I \& II) were confirmed in the populations using this clustering analysis. Clusters I, II and a pair of Clusters III \& IV nearly coincided with a pair of Group $\operatorname{Tree}_{\text {Tre }} 2$ \& 3, Group Tree $_{4} 4$ and Group Tree $_{1} 1$ in the phylogenetic tree, respectively (Fig. 7). Moreover, the presence of the mixed genetic population, which could not be usually detected in a phylogenetic tree, was founded by the cluster analysis. As discussed in the previous studies [69-71, 73], this admixture of Cluster I \& II may be established through gene flow caused by migrant; thus, events relative to individual movement and breeding could have occurred among some populations in the past. 


\section{Conclusions}

A series of the exhaustive genetic analysis in this chapter demonstrated that the populations of the Hotoke loach indicated to have moderate genetic diversity and to be supported with 4 genetic populations, of which distributions depended on the populations and the geographical locations. These 2 genetic characteristics showed that there could not be serious genetic concerns at present and the populations might be available as valuable biological resources such as bird food. To fulfill the effective utilization of this loach in near future, both biomedical and nutritional investigations for component contained in the body may also have to be practiced in the next research subjects along with proposing an optimal management plan for conserving the populations.

Further, the following 2 suggestions based on the results of this analysis should be realized in conduct of the next research. First, to sustain the present genetic features, habitats of the populations have to be maintained with monitoring the population size. As it is repeatedly described in the above, but reduction of the population size often appears to cause degradation of the genetic diversity and the lost genetic diversity could never be regained in the populations [30-33]. Avoiding such a decrease in the genetic diversity, habitat conservation might be important for a population management. It was also investigated that this species had relatively strict water temperature resistance compared with other common freshwater fish [48, 49]; hence the control of the water quality, especially water temperature could be one of essential factors for conserving habitats of the populations.

Second, spatial distribution and composition of the genetic populations should be taken account in the population management. In this area the genetic populations could be established by only geographical factors such as river and ground conditions (Fig. 9) and related to no human activities. The foregoing genetic populations often appear a kind of genetic heritages and it is recommended that their distributions do not have to be disturbed artificially [30-33, 35]. If perchance size diminishment of a specific population is observed and there is only individual translocation as a method to recover the population, selections of translated individuals and populations should be advisedly carried out based on the distribution of the genetic populations. Finally there still may be various and many biological resources left in the rural ecosystem in Japan. Genetic analyses performed in this chapter would have to contribute substantially to exploration and beneficial utilization of these resources.

\section{Acknowledgement}

Our thanks go to Drs Wataru Kakino and Shin-ichi Matsuzawa, Mr. Masumi Matsuzaki and Ms. Zhenli Gao for their aggressive supports in the research field and Mses. Chikusa Suzuki, Ponthip Goto and Kyoko Yamanoi for their assistance in DNA chemical analyses, including valuable discussions with Dr. Hiroshi Aiki. The first author would like to kindly appreciate Dr. Gandhi Rádis Baptista for his invitation to this book and Mses. Adriana Pecar, Ivana Zec and Masa Vidovic and Mr. Dejan Grgur for their thoughtful helps in the publishing process 
for this manuscript. This study was supported in part by a Grant-in-Aid for Scientific Research (C-18580250, C-20580270, C-23580340, B-18380139 and B-22380133) from the Japan Society for the Promotion of Science.

\section{Author details}

Noriyuki Koizumi ${ }^{1}$, Masakazu Mizutani ${ }^{2}$, Keiji Watabe ${ }^{1}$, Atsushi Mori ${ }^{1}$, Kazuya Nishida ${ }^{1}$ and Takeshi Takemura ${ }^{1}$

1 Institute for Rural Engineering, National Agriculture and Food Research Organization, Ibaraki, Japan

2 Faculty of Agriculture, Utsunomiya University, Utsunomioya, Japan

\section{References}

[1] Honda Y (2009) How do the local people think about the release of Toki (Nipponia nippon) just before the release?: from the questionnaire survey in whole Sado-city. Bulletin of the Tokyo University Forests, 121, 149-172. (in Japanese with English abstract)

[2] Naito K, Kikuchi N, Ikeda H (2011) Reintroduction of oriental white storks: ecological restoration and preparation for release into the wild based on the guidelines of IUCN. Japanese Journal of Conservation Ecology, 16, 181-193. (in Japanese with English abstract)

[3] National Institute for Agro-Environmental Sciences (1998) Biodiversity of Paddy Field Ecosystem. Yokendo Co., Ltd., Tokyo. (in Japanese)

[4] Makino H (1996) Dojo Loach. Rural Culture Association Japan, Tokyo. (in Japanese)

[5] Suzuki R (1983) Latest Technology of the Dojo Loach Culture. Soubunkan, Tokyo. (in Japanese)

[6] Ezaki Y, Tanaka T (1998) Conservation of Waterfront Environment. Asakura Publishing Co., Ltd., Tokyo. (in Japanese)

[7] Nakagawa S (2000) Biotope in Rural Area. Shinzansha Publisher Co., Ltd., Tokyo. (in Japanese)

[8] Mizutani M (2007) An Introduction to Paddy Field Eco-engineering for Sustaining and Restoring Biodiversity in Rural Areas. Rural Culture Association Japan, Tokyo. (in Japanese)

[9] Mizutani M, Mori A (2009) Conserving Habitat of Freshwater Fishes Inhabiting Harunoogawa, Irrigation/Drainage Ditches, in Rice Paddies. Gakuhosya, Tokyo. (in Japanese) 
[10] Japan Ministry of the Environment (2003) Threatened Wildlife of Japan, Red Data Book. Japan Wildlife Research Center, Tokyo. (in Japanese)

[11] Mitsuo Y, Nishida K, Senga Y (2007) A research on habitat condition of Hotoke loach in "Yatu" waters: case study of the upper stream of the Okuri River. Irrigation, Drainage and Rural Engineering Journal, 75, 445-451. (in Japanese with English abstract)

[12] Moriyama T, Mizutani M, Goto A (2007) Seasonal migration of Hotoke-dojo loach Lefua echigonia in a spring-derived stream, Nishikinugawa district, Tochigi Prefecture, Japan. Japanese Journal of Ichthyology, 54, 161-171. (in Japanese with English abstract)

[13] Fujita H, Okawa K (1975) A preliminary survey of geographic variations of cobitid fish, Lefua echigonia, in Japan. Japanese Journal of Ichthyology, 22, 179-182. (in Japanese with English abstract)

[14] Hosoya K (2000) Cobitidae. In Nakabo T (ed.) Fishes of Japan with Pictorial Keys to the Species, Tokai University Press, Tokyo, p272-277. (in Japanese)

[15] Mochida M, Kuramoto N (2007) Study on native habitat of Hotoke loach, Lefua echigonia to live on Yato after farmlad consolidation. Papers on Environmental Information Science, 21, 117-122. (in Japanese with English abstract)

[16] Kitano S, Yamagata T, Yagyu M (2008) Distribution, habitat characteristics, and mitochondrial DNA haplotypes of Lefua echigonia in Nagano Pref., central Japan. Bulletin of Nagano Environmental Conservation Research Institute, 4, 45-50. (in Japanese with English abstract)

[17] Aiki H, Mano N, Sasada K, Shimada M, Hirose H (2008) Distribution and present status of Japanese eight-barbel loach Lefua echigonia (Jordan et Richardson, 1907) in Fukushima Prefecture, Japan. Bulletin of the Bio-geographical Society of Japan, 63, 5-11. (in Japanese with English abstract)

[18] Moriyama T, Kakino W, Mizutani M (2010) Winter distribution pattern of Japanese eight-barbel loach in a conservation pond supplied with pumped groundwater. Japanese Journal of Ichthyology, 57, 161-166. (in Japanese with English abstract)

[19] Suguro N, Suzuki M, Mizutani M (2008) Study of a fish way suitable for Hotoke loach (Lefua echigonia). Bulletin of the Kanagawa Prefectural Fisheries Technology Center, 3, 87-95. (in Japanese with English abstract)

[20] Mitsuo Y, Nishida K, Senga Y (2010) Utilization of paddy field by Hotoke loach: Case study of Yatsu paddy field in the upper stream of the Okuri River. Wildife Conservation Japan, 12, 1-9. (in Japanese with English abstract)

[21] Suguro N (2002) Early rearing conditions of Hotoke loach, Lefua echigonia. Aquaculture Science, 50, 55-62. (in Japanese with English abstract) 
[22] Suguro N (2005) Numbers of parental fish and artificial spawning beds that result in maximum seed production in Lefua echigonia. Aquaculture Science, 53, 83-90. (in Japanese with English abstract)

[23] Miyamoto R, Suguro N, Hosoya K (2009) Artificial propagation of an endangered freshwater fish, the Hotoke loach Lefua echigonia Jordan et Richardson. Memoirs of the Faculty of Agriculture of Kinki University, 42, 119-126. (in Japanese with English abstract)

[24] Sakai T, Mihara M, Shitara H, Yonekawa H, Hosoya K, Miyazaki J (2003) Phylogenetic relationships and intraspecific variations of loaches of the genus Lefua (Balitoridae, Cypriniformes). Zoological Science, 20, 501-514.

[25] Saka R, Takehana Y, Suguro N, Sakaizumi M (2003) Genetic population structure of Lefua echigonia inferred from allozymic and mitochondrial cytochrome $b$ variations. Ichthyological Research, 50, 301-309.

[26] Mihara M, Sakai T, Nakano K, Martins OL, Hosoya K, Miyazaki J (2005) Phylogeography of loaches of the genus Lefua (Balitoridae, Cypriniformes) inferred from mitochondrial DNA sequences. Zoological Science, 22, 157-168.

[27] Aiki H, Takayama K, Tamaru T, Mano N, Shimada M, Komaki H, Hirose H (2009) Phylogeography of the Japanese eight-barbel loach Lefua echigonia from the Yamagata area of the Tohoku district, Japan. Fisheries Science, 75, 903-908.

[28] Koizumi N, Watabe K, Gao Z, Mizutani M, Takemura T, Mori A (2010) Haplotype of mitochondrial DNA for the Japanese eight-barbel loach in the southeast of Tochigi Prefecture. Irrigation, Drainage and Rural Engineering Journal, 78, 61-62. (in Japanese)

[29] Nishida K, Koizumi N, Takemura T, Watabe K, Mori A (2012) Mitochondrial DNA D-loop sequence-based analysis of the influence of river basin connectivity and fragmentation on the genetic structure and diversity of the Japanese eight-barbel loach Lefua echigonia. Technical Report of National Institute for Rural Engineering, 212, 177-188. (in Japanese with English abstract)

[30] Loeschcke V, Tomiuk J, Jain SK (1994) Conservation Genetics. Birkhäuser Verlag, Boston.

[31] Avise JC, Hamric JL (1996) Conservation Genetics. Chapman and Hall, New York.

[32] Smith TB, Wayne RK (1996) Molecular Genetic Approaches in Conservation. Oxford University Press, New York.

[33] Frankham R, Ballou JD, Briscoe DA (2002) Introduction to Conservation Genetics. Cambridge University Press, Cambridge.

[34] The Society for the Study of Species Biology (2001) Molecular Ecology of Woody Species. Bun-ichi Sogo Shuppan Co., Tokyo. (in Japanese)

[35] Koike Y, Matsui M (2003) Conservation Genetics. University of Tokyo Press, Tokyo. (in Japanese) 
[36] Koizumi N, Takahashi H, Minezawa M, Takemura T, Okushima S, Mori A (2007). Isolation and characterization of polymorphic microsatellite DNA markers in the Japanese eight-barbel loach, Lefua echigonia. Molecular Ecology Notes, 7, 836-838.

[37] Koizumi N, Watabe K, Gao Z, Mizutani M, Mori A, Takemura T (2008) Preliminary study on genetic population of the Japanese eight-barbel loach in the upper Kokai River basin, Tochigi Prefecture using microsatellite DNA. Irrigation, Drainage and Rural Engineering Journal, 76, 397-403. (in Japanese with English abstract)

[38] Koizumi N (2009) Conservation of freshwater fishes using information obtained by DNA analysis. In Mizutani M, Mori A (ed.) Conserving Habitat of Freshwater Fishes Inhabiting Haruno-ogawa, Irrigation/Drainage Ditches, in Rice Paddies, Gakuhosya, Tokyo, p121-148. (in Japanese)

[39] Koizumi N, Hanamura Y, Quinn TW, Nishida K, Takemura T, Watabe K, Mori A, Man A (2012) Thirty-two polymorphic microsatellite loci of the mysid crustacean Mesopodopsis tenuipes. Conservation Genetic Resources, 4, 55-58.

[40] Koizumi N, Quinn TW, Jinguji H, Nishida K, Watabe K, Takemura T, Mori A (2012) Development and characterization of 23 polymorphic microsatellite markers for Sympetrum frequens. Conservation Genetic Resources, 4, 67-70.

[41] Asahida T, Kobayashi T, Saitoh K, Nakayama I (1996) Tissue preservation and total DNA extraction from fish stored at ambient temperature using buffer containing high concentration of urea. Fisheries Science, 62, 727-730.

[42] Glenn TC, Schable NA (2005) Isolating microsatellite DNA loci. Methods in Enzymolo$g y, 395,202-222$.

[43] St. John J, Quinn TW (2008) Rapid capture of DNA targets. BioTechniques, 44, 259-264.

[44] Lorenz E, Frees KL, Schwartz DA (2001) M13-tailed primers improve the readability and usability of microsatellite analyses performed with two different allele-sizing methods. BioTechniques, 31, 24-27.

[45] Rousset F (2008) Genepop'007: a complete reimplementation of the Genepop software for Windows and Linux. Molecular Ecology Resources, 8, 103-106.

[46] van Oosterhout C, Hutchinson WF, Wills DPM, Shipley P (2004) Micro-Checker: software for identifying and correcting genotyping errors in microsatellite data. Molecular Ecology Notes, 4,535-538.

[47] Rice WR (1989) Analyzing tables of statistical tests. Evolution, 43, 223-225.

[48] Kakino W, Mizutani M, Fujisaku M, Goto A (2006) Influence of environmental factors on fish fauna distribution in hill-bottom valleys: case study of the upper stream of the Kokai River. Irrigation, Drainage and Rural Engineering Journal, 74, 809-816. (in Japanese with English abstract)

[49] Kakino W, Mizutani M, Fujisaku M, Goto A (2007) Seasonal changes of environmental factors influencing on fish population density in ditches of hill-bottom valleys lo- 
cated in the upper stream of the Kokai River, the Tone River basin. Irrigation, Drainage and Rural Engineering Journal, 75, 19-29. (in Japanese with English abstract)

[50] Mori A, Mizutani M, Matsuzawa S (2007) Origin estimation of carbon of spiders (Arachnida) by carbon stable isotope ratio. Irrigation, Drainage and Rural Engineering Journal, 75, 565-571. (in Japanese with English abstract)

[51] Matsuzawa S, Mizutani M, Mori A, Goto A (2008) Stable isotope ratio of organisms in small ditches used for irrigation and drainage in hill-bottom paddy fields. Irrigation, Drainage and Rural Engineering Journal, 76, 95-105. (in Japanese with English abstract)

[52] Kakino W, Mizutani M, Goto A (2009) Proposal of a fish habitat environmental model at hill-bottom valleys waters in Tochgi Prefecture. Irrigation, Drainage and Rural Engineering Journal, 77, 567-575. (in Japanese with English abstract)

[53] Park, SDE (2001) Trypanotolerance in West African Cattle and the Population Genetic Effects of Selection. PhD thesis, University of Dublin.

[54] El Mousadik A, Petit RJ (1996) High level of genetic differentiation for allelic richness among populations of the argan tree [Argania spinosa (L.) Skeels] endemic to Morocco. Theoretical and Applied Genetics, 92, 832-839.

[55] Peakall R, Smouse PE (2006) GENALEX 6: genetic analysis in Excel. Population genetic software for teaching and research. Molecular Ecology Notes, 6, 288-295.

[56] Goudet J (1999) FSTAT, a program to estimate and test gene diversities and fixation indices (version 2.9.3). University of Lausanne, Lausanne.

[57] Nei M (1987) Molecular Evolutionary Genetics. Columbia University Press, New York.

[58] Excoffier L, Laval G, Schneider S (2005) Arlequin ver. 3.0: An integrated software package for population genetics data analysis. Evolutionary Bioinformatics Online, 1, 47-50.

[59] Write S (1939) The distribution of self-sterility alleles in populations. Genetics, 24, 538-552.

[60] Kimura M, Crow J (1964) The number of alleles that can be maintained in a finite population. Genetics, 49, 725-738.

[61] Weir BS, Cockerham CC (1984) Estimating F-statistics for the analysis of population structure. Evolution, 38, 1358-1370.

[62] Hartl DL (1981) A Primer of Population Genetics. Sinauer Associates Inc., Massachusetts.

[63] Excoffier L, Smouse PE, Quattro JM (1992) Analysis of molecular variance inferred from metric distances among DNA haplotypes: application to human mitochondrial DNA restriction data. Genetics, 131, 479-491. 
[64] Nei M, Tajima F, Tateno Y (1983) Accuracy of estimated phylogenetic trees from molecular data. Journal of Molecular Evolution, 19, 153-170.

[65] Saitou N, Nei M (1987) The neighbor-joining method: a new method for reconstructing phylogenetic trees. Molecular Biology and Evolution, 4, 406-425.

[66] Felsenstein J (1985) Confidence limits on phylogenies: an approach using the bootstrap. Evolution, 39, 783-791.

[67] Langella O (2007) Populations 1.2.31. http://bioinformatics.org/ tryphon/populations/ (accessed 12 June 2012).

[68] Tamura K, Peterson D, Peterson N, Stecher G, Nei M, Kumar S (2011) MEGA5: molecular evolutionary genetics analysis using maximum likelihood, evolutionary distance, and maximum parsimony methods. Molecular Biology and Evolution, 28, 2731-2739.

[69] Pritchard JK, Rosenberg NA (1999) Use of unlinked genetic markers to detect population stratification in association studies. The American Journal of Human Genetics, 65, 220-228.

[70] Pritchard JK, Stephens M, Donnelly P (2000) Inference of population structure using multilocus genotype data. Genetics, 155, 945-959.

[71] Falush D, Stephens M, Pritchard JK (2003) Inference of population structure using multilocus genotype data: linked loci and correlated allele frequencies. Genetics, 164, 1567-1587.

[72] Manel S, Gaggiotti OE, Waples RS (2005) Assignment methods: matching biological questions with appropriate techniques. Trends in Ecology and Evolution, 20, 136-142.

[73] Falush D, Stephens M, Pritchard JK (2007) Inference of population structure using multilocus genotype data: dominant markers and null alleles. Molecular Ecology Notes, 7, 574-578.

[74] Hubisz M, Falush D, Stephens M, Pritchard J (2009) Inferring weak population structure with the assistance of sample group information. Molecular Ecology Resources, 9, 1322-1332.

[75] Evanno G, Regnaut S, Goudet J (2005) Detecting the number of clusters of individuals using the software STRUCTURE: a simulation study. Molecular Ecology, 14, 2611-2620.

[76] Earl DA, vonHoldt BM (2012) STRUCTURE HARVESTER: a website and program for visualizing STRUCTURE output and implementing the Evanno method. Conservation Genetics Resources, 4, 359-361.

[77] Jakobsson M, Rosenberg NA (2007) CLUMPP: a cluster matching and permutation program for dealing with label switching and multimodality in analysis of population structure. Bioinformatics, 23, 1801-1806. 
[78] Frankham R (2000) Modeling problems in conservation genetics using laboratory animals. In Ferson S, Burgman M (ed.) Quantitative Methods in Conservation Biology, Springer-Verlag, New York, p259-273.

[79] Koizumi N, Takemura T, Mori A, Okushima S (2009) Genetic structure of loach population in Yatsu paddy field. Irrigation, Drainage and Rural Engineering Journal, 77, 253-261. (in Japanese with English abstract)

[80] Koizumi N, Takahashi H, Minezawa M, Takemura T, Okushima S (2007) Fourteen polymorphic microsatellite loci in the field gudgeon, Gnathopogon elongatus elongates. Molecular Ecology Notes, 7, 240-242.

[81] Ohara K, Hotta M, Takahashi D, Asahida T, Ida H, Umino T (2009) Use of microsatellite DNA and otolith Sr:Ca ratios to infer genetic relationships and migration history of four morphotypes of Rhinogobius sp. OR. Ichthyological Research, 56, 373-379.

[82] Randall1 DA, Pollinger JP, Argaw K, Macdonald DW, Wayne RK (2010) Fine-scale genetic structure in Ethiopian wolves imposed by sociality, migration, and population bottlenecks. Conservation Genetics, 11, 89-101.

[83] Brown VA, Brooke A, Fordyce JA, McCracken GF (2011) Genetic analysis of populations of the threatened bat Pteropus mariannus. Conservation Genetics, 12, 933-941.

[84] Docker MF, Heath DD (2003) Genetic comparison between sympatric anadromous steelhead and freshwater resident rainbow trout in British Columbia, Canada. Conservation Genetics, 2, 227-231.

[85] Massa-Gallucci A, Coscia I, O'Grady M, Kelly-Quinn M, Mariani S (2010) Patterns of genetic structuring in a brown trout (Salmo trutta L.) metapopulation. Conservation Genetics, 11, 1689-1699.

[86] Lloyd MW, Burnett RK, Engelhardt KAM, Neel MC (2011) The structure of population genetic diversity in Vallisneriaamericana in the Chesapeake Bay: implications for restoration. Conservation Genetics, 12, 1269-1285.

[87] Junker J, Peter A, Wagner CE, Mwaiko S, Germann B, Seehausen O, Keller, I (2012) River fragmentation increases localized population genetic structure and enhances asymmetry of dispersal in bullhead (Cottus gobio). Conservation Genetics, 13, 545-556.

[88] Rodriguez D, Forstner MRJ, McBride DL, Densmore LD, Dixon JR (2012) Low genetic diversity and evidence of population structure among subspecies of Nerodia harteri, a threatened water snake endemic to Texas. Conservation Genetics, 13, 977-986. 